Original

\title{
Histological analysis of effects of $24 \%$ EDTA gel for nonsurgical treatment of periodontal tissues
}

\author{
Luana Marotta Reis de Vasconcellos ${ }^{1)}$, \\ Lucilene Hernandes Ricardo ${ }^{2)}$, Ivan Balducci' ${ }^{3)}$, \\ Luis Gustavo Oliveira de Vasconcellos ${ }^{4}$ \\ and Yasmin Rodarte Carvalho ${ }^{1)}$ \\ ${ }^{1)}$ Department of Bioscience and Buccal Diagnosis, Dental School of São José dos Campos, \\ State University of Sao Paulo, São José dos Campos, Brazil \\ ${ }^{2)}$ Department of Periodontology, Dental School of Taubate, University of Taubate, Taubate, Brazil \\ ${ }^{3)}$ Department of Social Odontology and Pediatric Clinic, Dental School of São José dos Campos, \\ State University of Sao Paulo, São José dos Campos, Brazil \\ 4)Alameda. Harvey C. Weeks, São José dos Campos, Brazil
}

(Received 1 May and accepted 19 September 2006)

\begin{abstract}
The aim of this study was to investigate, by means of histological and histomorphometric analysis, the effects of $24 \%$ ethylenediaminetetraacetic acid (EDTA) gel in periodontal tissue when used in combination with conventional periodontal treatment. Periodontitis was induced in the 2nd upper left permanent molars of $\mathbf{4 5}$ male Wistar rats by means of ligature. After 5 weeks, this was removed and debridement was performed. The animals were then randomly divided into 3 groups; group 1: mechanical treatment, group 2: mechanical treatment and EDTA gel application for $2 \mathrm{~min}$, and group 3: mechanical treatment and placebo gel application for $2 \mathrm{~min}$. After the treatment, rinsing was done with $0.9 \%$ saline solution for $1 \mathrm{~min}$ in all cases, followed by root notching in the deepest part of the pocket. After 4, 10, and 28 days the animals were sacrificed. The averages obtained were evaluated by means of test two-way analysis of variance (ANOVA) and Tukey statistical tests $(P<$ $0.05)$. The results showed that with respect to the type of treatment employed, there were no statistically
\end{abstract}

Correspondence to Dr. Luana Marotta Reis de Vasconcellos, Alameda Harvey C. Weeks, n.14, sl.09 Vista Verde, São José dos Campos, SP CEP: 12.223-840, Brazil

Tel: +55-12-3912-2342

Fax: +55-12-3122-6019

E-mail: luana@fosjc.unesp.br significant differences in the vitality of the periodontal tissue. It was concluded that $24 \%$ EDTA gel did not interfere with periodontal tissue repair when used in combination with conventional periodontal treatment. (J. Oral Sci. 48, 207-214, 2006)

Keywords: dental scaling; periodontitis; EDTA; acid etching; histology.

\section{Introduction}

Periodontal regeneration has always been the ultimate goal of periodontal treatment. Perhaps the most frequently attempted type of regeneration has involved chemical modification of the root surface (1). The purpose of this chemical modification is mainly to remove the smear layer that results from scaling and root planning $(2,3)$, to remove endotoxins, to open dentinal tubules, as well as to expose collagen fibers from root surfaces (4-7). Therefore chemical modification has been used as an adjunct to scaling and root planning to facilitate reattachment of periodontal ligament fibers $(3,8)$. One of the most widely used agents for this purpose is citric acid (9). However, other agents such as tetracycline (10-12) and ethylenediaminetetraacetic acid (EDTA) $(6,13,14)$ have also been employed.

Some authors claim that low-pH biomodification agents 
may have necrotizing effects, whereas neutral-pH agents do not $(7,15)$. The use of EDTA gel at neutral $\mathrm{pH}$ as an etching agent provides better removal of the smear layer, dissolves parts of the mineralized root surface, selectively exposing collagen fibers, and also favors the migration and attachment of fibroblasts $(4,6,8,16)$. Studies that have assessed EDTA gel as an adjunct to periodontal treatment, using scanning electron microscopy (SEM), have shown that it is effective in exposing collagen fibers and removing the smear layer on the root surface $(7,17,18)$, and does not induce any detectable necrosis of the surrounding vital periodontal tissue (10). However, there has been no attempt to evaluate histologically the morphologic features of periodontal tissues when EDTA gel is used as an adjunct to conventional periodontal treatment.

The aim of this study was to assess, by means of histological and histomorphometric analysis, the effect of $24 \% \mathrm{pH} 7.0$ EDTA gel on the vitality of periodontal tissues, when used as an adjunct to conventional periodontal treatment.

\section{Materials and Methods}

Forty-five male Wistar rats (body weight 200 to $250 \mathrm{~g}$ ), supplied by the vivarium of the Dental School of São José dos Campos, Sao Paulo, Brazil, were used in this study. The study was approved by the University Research Ethics Committee. The animals were maintained in cages in groups of 3 per cage, and supplied with food and water ad libitum. Before treatment, general anesthesia was induced by an intramuscular injection of $0.1 \mathrm{ml} / 100 \mathrm{~g}$ body weight Cloridrate:Ketamine in a 1:0.5 ratio.

\section{Experimental outline}

Periodontal disease was induced using a cotton ligature

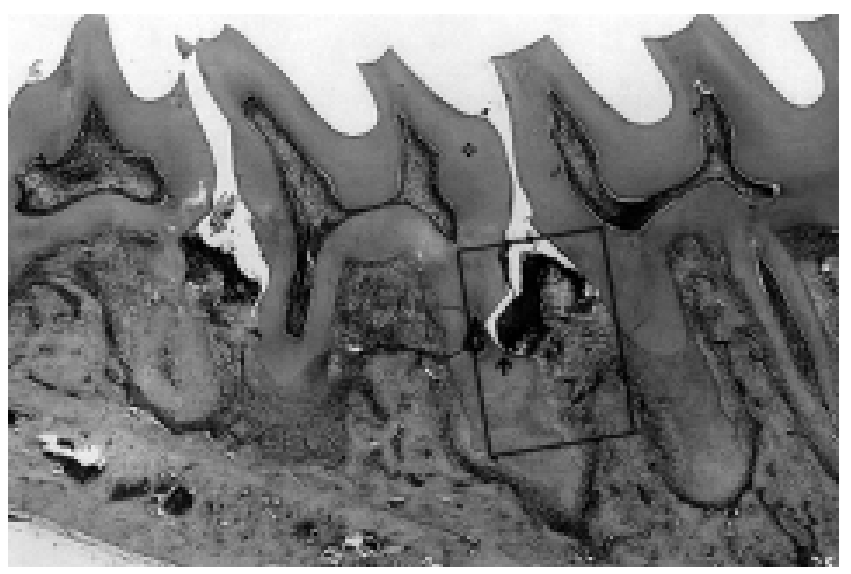

Fig.1 Panoramic view of rat molars with induced periodontal disease: tooth $(\$)$, notch in the root surface $(\rightarrow)$. Original magnification $\times 25-\mathrm{H}-\mathrm{E}$. placed around the second upper left permanent molar of the animals (Fig. 1), with the aim of accumulating plaque and developing periodontitis (19). The ligature was maintained for five weeks $(19,20)$ in the gingival sulcus, and during this period its position was verified weekly. If the ligature was found to have been lost, it was replaced. After five weeks, the ligature was removed and the root surface was debrided with a specially adapted McCall 13/14 curet (mechanical treatment) whose active area had been reduced. Root planing was carried out on the mesial, distal, buccal and lingual faces of the tooth, with the aim of removing bacterial plaque, calculus and inflamed tissue. Thereafter, the deepest part of the periodontal pocket was notched at the root surface by inserting a Hedströen endodontic file (Dentsply-Maillefer, Petrópolis, RJ, Brazil) \#15 into the interproximal space. All procedures were carried out without periodontal surgery.

The animals were randomly divided into 3 experimental groups of 15 animals each: group 1, mechanical treatment; group 2, mechanical treatment and application of 24\% EDTA gel for 2 min; group 3, mechanical treatment and application of placebo gel for $2 \mathrm{~min}$. The 24\% EDTA gel and placebo gel were applied to the root surface, within periodontal pockets, with a syringe and retained there for 2 min. After etching, the treated areas were rinsed with $0.9 \%$ saline solution for $1 \mathrm{~min}$. After a healing period of 4,10 or 28 days, five rats in each group were sacrificed with an overdose of Cloridrate:Ketamine, and tissue samples were removed and prepared for histological and histomorphometric evaluation.

Histological and histomorphometric evaluation

Maxilla fragments containing the molars were fixed in $10 \%$ formaldehyde solution for $48 \mathrm{~h}$, demineralized in $60 \%$ formic acid for approximately 15 days, infiltrated and embedded in paraffin, and serially sectioned $(5 \mu \mathrm{m})$ in the bucco-palatal direction, parallel to the long axis of the tooth, and stained with hematoxylin and eosin (H-E). Histological analysis was done using a light microscope (Axioplan 2, Zeiss, Oberkochen, Germany), focusing on inflammatory response and periodontal tissue repair.

Histomorphometric analysis was carried out at $\times 20$ magnification using a grid that divided the field into 100 equal parts. The grid was placed over the tissue that filled the notch in the root surface (Fig. 2). The total number of intersections for each tissue type - epithelium, inflamed connective tissue, healthy connective tissue, and total field - was then counted. The number of units was divided by the total number of intersections and expressed as a percentage $(2,21)$. 


\section{Statistical analysis}

Data on periodontal repair were analyzed separately for each type of tissue, and the data are presented as means and standard deviations. The significance of differences among mean values for the groups was tested using twoway analysis of variance (ANOVA) and the Tukey's multiple comparison test. Differences were regarded as statistically significant at $P<0.05$ and data were analyzed using a software program (STATIXTIX for Windows 2000, 7.0 version, Anaytical Software).

\section{Results \\ Histologic observations}

The rats seemed to tolerate the experiments well and no adverse reactions were noticed during the observation period. All animals showed apical migration of epithelial attachment, irregularity of the alveolar bone crest, and loosening of supracrestal and ligament fibers, including the furcation region, and occasionally the presence of bone sequestrum was noted. Notching of the root surface, fur, biofilm and cracks between the root surface and soft tissue were also observed.

As the morphologic features observed in the groups with different treatments were similar, the description was based on sacrifice period (4, 10 or 28 days). The gingival epithelium at four days after the treatment, regardless of the treatment used, showed necrosis of the most superficial layer and an intense increase in its thickness (Figs. 3, 4).

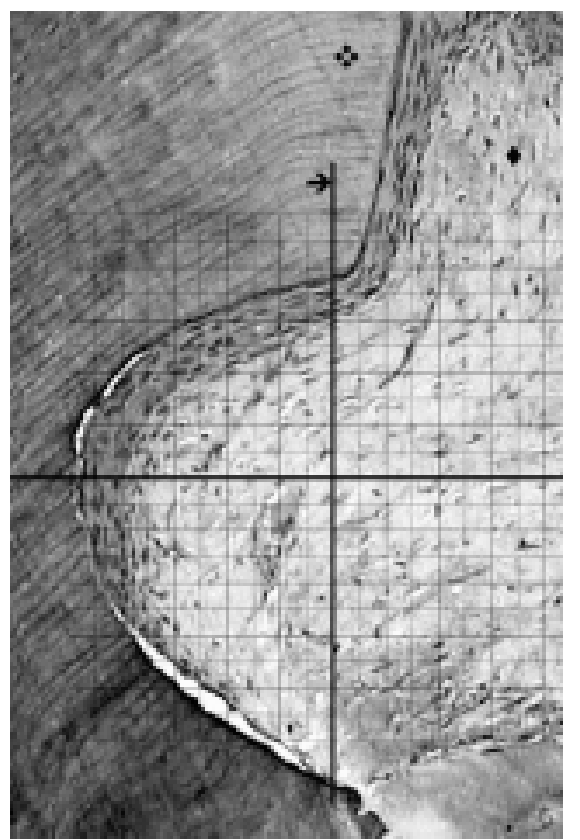

Fig. 2 The grid $(\rightarrow)$ placed over the tissue that filled the notch in the root surface. Root surface ( ), and periodontal tissue $(\diamond)$. Original magnification $\times 100$ H-E.
In these animals, and the animals sacrificed at 10 days after the treatment, the junctional epithelium exhibited larger and more numerous projections towards the lamina propria

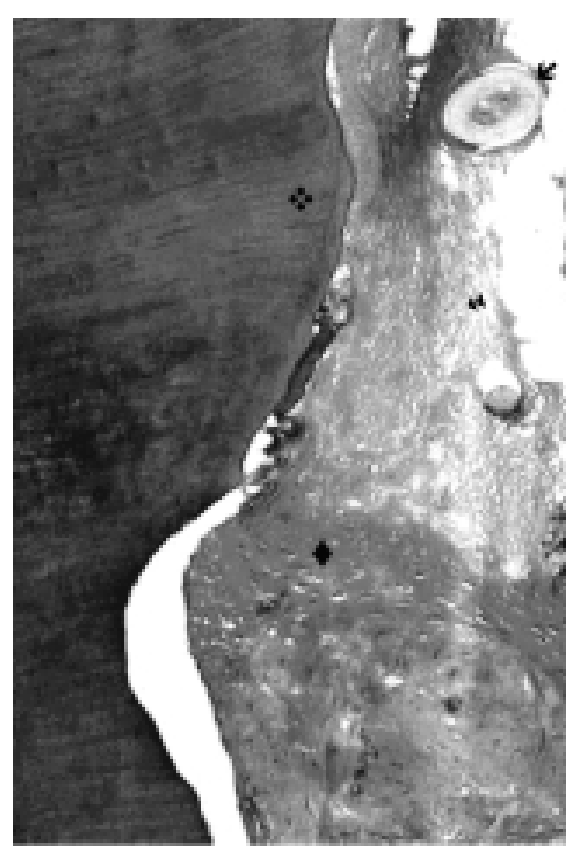

Fig. 3 Photomicrograph of sample from a rat sacrificed at four days after mechanical treatment: root surface $(\$)$, epithelial migration $(\rightarrow)$, fur $(\rightarrow)$, and presence of necrosis in the most superficial layer $(\boldsymbol{W})$. Original magnification $\times 50$ - $\mathrm{H}$-E.

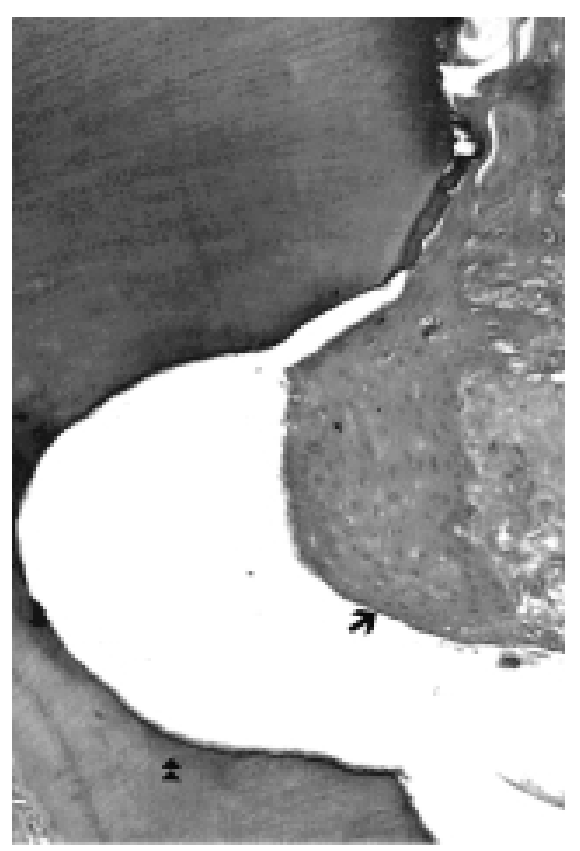

Fig. 4 Photomicrograph of sample from a rat sacrificed at four days after treatment with EDTA gel: root surface $(\$)$, epithelial migration $(\rightarrow)$. Original magnification $\times 50$ - H-E. 
(Fig. 5). The connective tissue in the animals sacrificed at four days showed a greater quantity of fibrin, edema, and moderate inflammatory cell infiltration comprising predominantly neutrophils and macrophages, especially in the subepithelial region. Inflammatory cell infiltration decreased with time, and no periodontal inflammation was observed at 28 days.

The animals sacrificed at 4 and 10 days showed a large amount of fibroblasts and collagen fibers with varied orientations, whereas in the animals sacrificed after 28 days, the lamina propria exhibited thicker collagen fibers interspersed by fusiform fibroblasts, arranged in a more orderly manner, and tending to be aligned parallel to the long axis of the root surface (Figs. 6-8).

The epithelium became thinner and more elongated with time, resulting in a long junctional epithelium, and the interface epithelium-connective tissue usually became flat. Furthermore, downgrowth of the epithelium sometimes stopped at the coronal level of the notch, but sometimes extended beyond it (Figs. 6-8).

\section{Histometric observations}

Intragroup analysis of epithelial tissue $(P=0.008)$, inflamed and healthy connective tissue $(P=0.0000)$, and total field $(P=0.0005)$ revealed a statistically significant difference in terms of sacrifice period (Table 1). On the

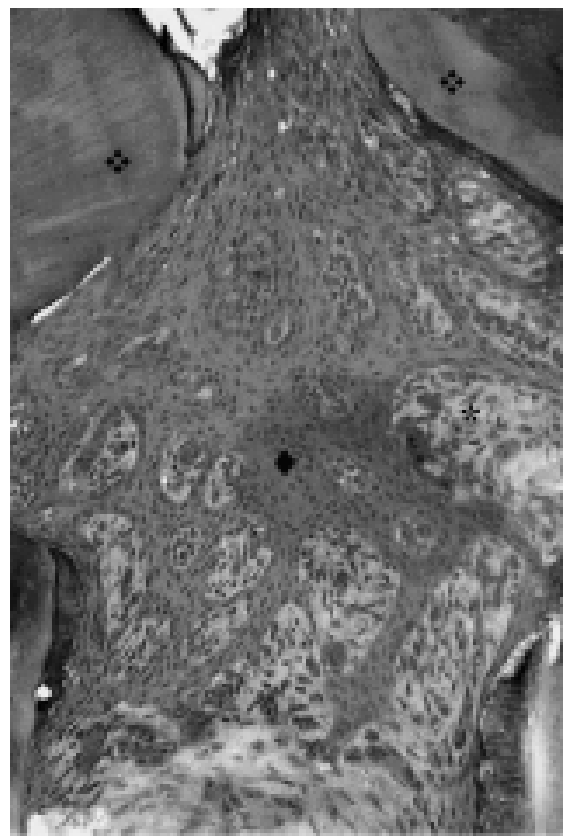

Fig. 5 Photomicrograph of sample from a rat sacrificed at 10 days after treatment with EDTA gel: root surface (\$), epithelial projections $(\diamond)$ and inflammatory cell infiltrate, especially in the subepithelial region $(*)$. Original magnification $\times 50$ - H-E. other hand, intergroup analysis did not show any significant differences with regard to treatment.

\section{Discussion}

The purpose of the present study was to assess the effects of $24 \% \mathrm{pH} 7.0$ EDTA gel on vitality of periodontal tissue when used as an adjunct with conventional (nonsurgical) periodontal therapy. The results showed that the EDTA gel did not promote additional necrotizing effects in the cells of the epithelium and connective tissue, and that there were no significant differences in terms of periodontal repair among the three treatments used.

In this study, the animals generally showed apical migration of the junctional epithelium, inflammatory cells and vessels in the connective tissues, loosening of periodontal ligament fibers, alveolar bone resorption, cementum rupture, and occasionally the presence of bone sequestrum. These features have also been reported by other authors $(19,20,22,23)$.

All rats assessed in the present study showed periodontal repair through formation of long junctional epithelium, due to the fact that the epithelium proliferates faster than other tissues, as reported by Melcher (24). However, the rate of proliferation differed among the animals, so that epithelial downgrowth sometimes stopped at the coronal level of the notch, and sometimes extended beyond it. In general, the

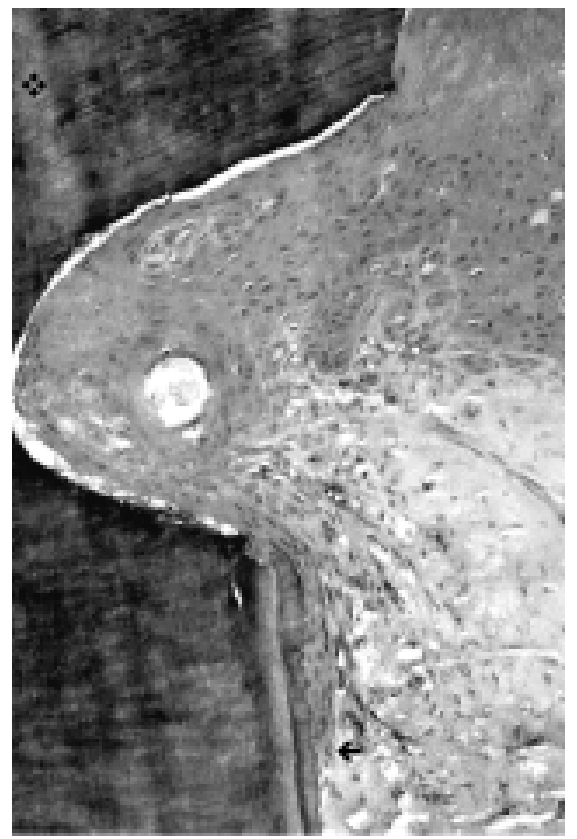

Fig. 6 Photomicrograph of sample from a rat sacrificed at 28 days after mechanical treatment (control group): root surface ( ) epithelium proliferating towards the apical direction exceeding the notch $(\rightarrow)$. Original magnification $\times 100-\mathrm{H}$-E. 
gingival tissue of rats shows features similar to those in man $(20,25,26)$, and for this reason rats have often been used in studies of periodontal disease $(20,22,23,27,28)$.

Several previous studies that have assessed the effects of EDTA gel as a coadjuvant in periodontal treatment focused on the root surface of human teeth extracted due to severe periodontitis. The purpose of these studies was to analyze the surface topography of periodontally affected human tooth roots after application of EDTA gel with different combinations of treatments $(4,5,7,12,16-18,29,30)$. The authors concluded that root surfaces treated with EDTA appeared to be more suitable for cellular colonization and subsequent connective tissue formation $(4,5)$, and exhibited numerous dentinal tubules exposed by removal of the smear layer $(7,12,16,17,29)$, and an intact collagenous matrix $(18,30)$. In view of these promising results, it seems important to study the effect of EDTA gel on soft periodontal tissue.

After root surface instrumentation, areas of contaminated cementum (31), as well as a smear layer produced during mechanical debridement, may still remain on instrumented surfaces, interfering with periodontal repair $(3,16)$. Therefore, chemical treatment of the root surface after scaling and root planing has been introduced as a promising procedure for removing the smear layer $(3,12,16$,$) and$ hypermineralized areas of the root surface, in order to

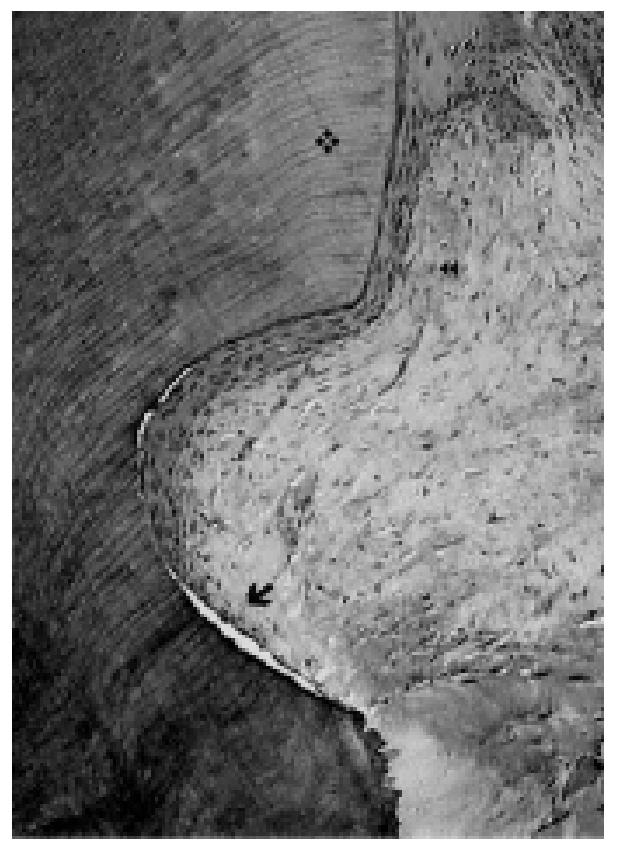

Fig. 7 Photomicrograph of sample from a rat sacrificed at 28 days after treatment with EDTA gel: root surface (*), epithelium proliferating towards the apical direction $(\rightarrow)$, and fibroblasts tending to show a parallel orientation $(\gg)$. Original magnification $\times 100-\mathrm{H}-\mathrm{E}$. expose collagen fibers and render the root surface biocompatible with periodontal cells $(11,29)$. Furthermore, acid etching may also facilitate the attachment of connective tissue $(3,8,11)$. However, etching of root surfaces at low $\mathrm{pH}$ has been shown to impair periodontal healing (2) in comparison with etching at neutral $\mathrm{pH}(10)$, since the use of low-pH biomodification agents may have necrotizing effects $(7,15)$. Thus, the beneficial smear-removing capacity of citric acid is diminished by its low $\mathrm{pH}$, which necrotizes the surrounding periodontal tissue cells and jeopardizes its healing potential $(2,10)$. Furthermore, etching at low $\mathrm{pH}$ with phosphoric acid appears to erode the surface rather than selectively exposing collagen fibers, as evidenced by the resulting surface granulation (18).

The aim of the present study was to carry out histological

Table 1 Mean \pm standard deviation of periodontal repair measurements expressed as percentages

\begin{tabular}{ccccc}
\hline $\begin{array}{c}\text { TS } \\
\text { (days) }\end{array}$ & Epithelium & Inflamed CT & Healthy CT & Total Field \\
\hline 4 & $0.231 \pm 0.113 \mathrm{~A}$ & $0.218 \pm 0.092 \mathrm{~A}$ & $0.076 \pm 0.064 \mathrm{~A}$ & $0.526 \pm 0.089 \mathrm{~A}$ \\
10 & $0.177 \pm 0.074$ & $0.202 \pm 0.071$ & $0.173 \pm 0.102 \mathrm{~B}$ & $0.554 \pm 0.092$ \\
28 & $0.127 \pm 0.081 \mathrm{~B}$ & - & $0.550 \pm 0.156 \mathrm{C}$ & $0.675 \pm 0.111 \mathrm{~B}$ \\
\hline
\end{tabular}

CT: connective tissue, TS: sacrifice time

In the columns, means \pm SD followed by different letters are significantly different.

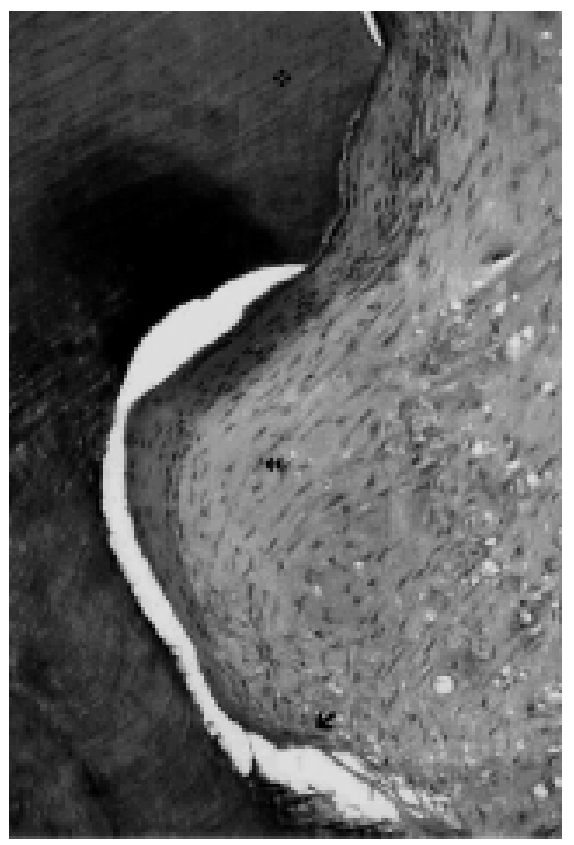

Fig. 8 Photomicrograph of sample from a rat sacrificed at 28 days after treatment with placebo gel: root surface $(\star)$, epithelium projection stopped at the coronal level of the notch $(\rightarrow)$, and fibroblasts tending to show a parallel orientation $(\gg)$. Original magnification $\times 100$ - H-E. 
analysis of the soft periodontal tissue (epithelium and connective tissue) after nonsurgical periodontal treatment, in order to evaluate the effects of EDTA. It was concluded that $24 \% \mathrm{pH} 7.0$ EDTA gel did not affect the vitality of periodontal tissue. Previous studies that used nonsurgical treatment to assess the influence of EDTA gel on periodontal tissue also concluded that EDTA preserved tissue vitality $(7,13)$. However, one of these studies presented only clinical scores (13) and the other merely observed the root surface after nonsurgical treatment (7) without histological analysis of the soft tissues. In addition, some earlier studies using surgical treatment to evaluate the effects of different etching modalities on periodontal healing also concluded that EDTA gel does not promote necrotization $(5,10,11,14)$.

In the present study, histological analysis of samples removed after 4 days showed necrosis of some cells in the superficial layer of the epithelium in all of the treatment groups, indicating that etching with EDTA gel at neutral $\mathrm{pH}$ did not induce additional cell necrosis. Furthermore, after 10 days, the group treated with EDTA gel exhibited a smaller amount of inflamed connective tissue than the other groups, although the difference was not statistically significant. This suggests that the EDTA gel removed the smear layer and endotoxins more efficiently and provided root surfaces that were more favorable for periodontal repair. Finally, in the animals sacrificed after 28 days, the lamina propria exhibited thicker collagen fibers interspersed by fusiform fibroblasts, showing a more orderly orientation parallel to the long axis of the root surface, without any differences among the groups. In some cases, irrespective of treatment and period before sacrifice, cracks between the tissue and the root surface were observed, although these were probably artifacts of histological preparation (23). Therefore, it can be concluded that the vitality of the surrounding periodontal tissue is not altered by application of EDTA gel, in accordance with earlier studies (5,7, 10,11,13,14).

Some studies have investigated the capacity of EDTA gel to enhance the healing of periodontal tissue $(11,13)$. Blomlöf et al. (11), using histological analysis, concluded that such treatment may increase total histological attachment (long epithelial junctions, connective tissue and reparative cementum). On the other hand, a more recent clinical analysis by Blomlöf et al. (13) showed no significant differences of insertion gain between a group treated with EDTA gel and a control group treated only by debridement. The aim of the present study was not to evaluate the influence of EDTA gel on periodontal regeneration, but to verify the effects of $\mathrm{pH}$-neutral EDTA gel on periodontal tissue. However, the results we obtained were similar to those of Blomlöf et al. (13) in that periodontal repair occurred through long junctional epithelium formation, and not through periodontal regeneration.

According to Blomlöf et al. (7), EDTA is an agent that chelates divalent cations, depleting culture medium of free calcium. During conventional periodontal therapy, the root surface inevitably becomes covered with blood mixed with debris from root planing, and this forms the smear layer. Blood, which contains divalent cations, may prevent EDTA from acting selectively on root surfaces to promote the exposure of collagen fibers. This could explain why the repair process did not improve (7). In addition, the subgingival plaque may be exposed to EDTA for a relatively short period, had minimal effect on periodontal repair $(5,18)$. In the present study, the gel was applied using a narrow-tipped syringe, and the objective was to cover all of the periodontal pocket field with gel. However, it could not be verified whether the gel penetrated and remained in the deepest region of the pocket for two minutes.

Previous in vitro studies with EDTA gel have proved that it alters the root surface and improves conditions for periodontal regeneration $(4-7,16-18,29,30)$. Root surface conditioning with EDTA during regenerative procedures may seem preferable to the use of citric or phosphoric acid because EDTA selectively removes hydroxyapatite, leaving most of the collagenous matrix intact $(14,18)$, thus aiding retention of implants of biologically active substances such as growth factors in addition to serving as a biocompatible surface for colonization of periodontal ligament cells (18). Furthermore, cleaning with EDTA is not dependent on a low $\mathrm{pH}$, nor does it present any toxicologic problems, thus avoiding the necrotizing effects of etching agents such as citric and phosphoric acid on surrounding periodontal tissues, as shown in the present and previous studies $(5,10,11,13,14)$.

\section{Conclusion}

The data obtained in the present study suggest that EDTA gel does not produce necrosis of cells in periodontal tissue. Therefore it does not alter the events of periodontal tissue repair, since the healing observed was similar in all of the studied groups. Histological analysis showed that the EDTA gel preserved the vitality of the surrounding periodontal tissues, and that the longer the time between treatment and sacrifice, the better the tissue repair obtained. Further studies are necessary to evaluate the exact role of EDTA gel conditioning of root surfaces in conventional periodontal therapy.

\section{Acknowledgments}

This work was supported by CAPES - Brazil. 


\section{References}

1. Mariotti A (2003) Efficacy of chemical root surface modifiers in the treatment of periodontal disease. A systematic review. Ann Periodontol 8, 205-226

2. Blomlöf J, Jansson L, Blomlöf L, Lindskog S (1995) Long-time etching at low $\mathrm{pH}$ jeopardizes periodontal healing. J Clin Periodontol 22, 459-463

3. Polson AM, Frederick GT, Ladenheim S, Hanes PJ (1984) The production of a root surface smear layer by instrumentation and its removal by citric acid. J Periodontol 55, 443-446

4. Bergenholtz A, Babay N (1998) Scanning electron microscopy of the root surface texture of extracted periodontally diseased teeth following various etching and chelating regimens. Int J Periodontics Restorative Dent 18, 171-179

5. Blomlöf J, Lindskog S (1995) Root surface texture and early cell and tissue colonization after different etching modalities. Eur J Oral Sci 103, 17-24

6. Blomlöf J, Blomlöf L, Lindskog S (1997) Effect of different concentrations of EDTA on smear removal and collagen exposure in periodontitis-affected root surfaces. J Clin Periodontol 24, 534-537

7. Blomlöf JPS, Blomlöf LB, Lindskog SF (1996) Smear removal and collagen exposure after nonsurgical root planning followed by etching with an EDTA gel preparation. J Periodontol 67, 841-845

8. Lasho DJ, O’Leary TJ, Kafrawy AH (1983) A scanning electron microscope study of the effects of various agents on instrumented periodontally involved root surfaces. J Periodontol 54, 210-220

9. Ricardo LH, Balducci I, Carvalho YR (2002) Root conditioning using TTC-HCL or citric acid: a histological study in rats. J Dent Res 81, A-293 (abstract)

10. Blomlöf J, Lindskog S (1995) Periodontal tissuevitality after different etching modalities. J Clin Periodontol 22, 464-468

11. Blomlöf J, Jansson L, Blomlöf L, Lindskog S (1996) Root surface etching at neutral $\mathrm{pH}$ promotes periodontal healing. J Clin Periodontol 23, 50-55

12. Isik AG, Tarim B, Hafez AA, Yalçin FS, Onan U, Cox CF (2000) A comparative scanning electron microscopic study on the characteristics of demineralized dentin root surface using different tetracycline $\mathrm{HCl}$ concentrations and application times. J Periodontol 71, 219-225

13. Blomlöf L, Bergman E, Forsgardh A, Foss L, Larsson A, Sjoberg B, Uhlander L, Jonsson B, Blomlöf J, Lindskog S (2000) A clinical study of root surface conditioning with an EDTA gel. I.
Nonsurgical periodontal treatment. Int J Periodontics Restorative Dent 20, 560-565

14. Blomlöf L, Jonsson B, Blomlöf J, Lindskog S (2000) A clinical study of root surface conditioning with an EDTA gel. II. Surgical periodontal treatment. Int J Periodontics Restorative Dent 20, 566-573

15. Kassab M, Cohen RE (2003) The effect of root modification and biomodification on periodontal therapy. Compend Contin Educ Dent 24, 36-37

16. Blomlöf JP, Blomlöf LB, Lindskog SF (1997) Smear layer formed by different root planning modalities and its removal by an ethylenediaminetetraacetic acid gel preparation. Int J Periodontics Restorative Dent 17, 242-249

17. Babay N (2000) Comparative SEM study on the effect of root conditioning with EDTA or tetracycline $\mathrm{HCl}$ on periodontally involved root surfaces. Indian J Dent Res 11, 53-57

18. Blomlöf J (1996) Root cementum appearance in healthy monkeys and periodontitis-prone patients after different etching modalities. J Clin Periodontol 23, 12-18

19. Galvão MP, Chapper A, Rosing CK, Ferreira MBC, de Souza MAL (2003) Methodological considerations on descriptive studies of induced periodontal diseases in rats. Pesqui Odontol Bras17, 56-62

20. Rodini CO (2005) Doença periodontal inflamatória induzida por ligadura: caracterização microscópica e estudo da presença de mastócitos e das enzimas óxido nítrico sintase induzível (inos) e metaloproteinases -2 e -9 . $\mathrm{PhD}$ thesis, University of Sao Paulo, Bauru, 1-149 (in Portuguese)

21. Eschler BM, Rapley JW (1991) Mechanical and chemical root preparation in vitro: efficiency of plaque and calculus removal. J Periodontol 62, 755760

22. Lindhe J, Ericsson I (1978) Effect of ligature placement and dental plaque on periodontal tissue breakdown in the dog. J Periodontol 49, 343-350

23. Listgarten MA (1972) Electron microscopic study of the junction between surgically denuded root surfaces and regenerated periodontal tissues. J Periodontal Res 7, 68-90

24. Melcher AH (1976) On the repair potential of periodontal tissues. J Periodontol 47, 256-260

25. Listgarten MA (1975) Similarity of epithelial relationships in the gingiva of rat and man. J Periodontol 46, 677-680

26. Klausen B (1991) Microbiological and immunological aspects of experimental periodontal 
disease in rats: a review article. J Periodontol 62, 59-73

27. Weinberg MA, Bral M (1999) Laboratory animal models in periodontology. J Clin Periodontol 26, 335-340

28. Wikesjö UME, Selvig KA (1999) Periodontal wound healing and regeneration. Periodontol 2000 19, 21 39

29. Blomlöf J, Blomlöf L, Lindskog S (1997) Ultrasonic subgingival root planning and EDTA etching in a one-step procedure. Swed Dent J 21, 213-219
30. Gamal AY, Mailhot JM (2003) The effects of EDTA gel conditioning exposure time on periodntitisaffected human root surfaces: surface topography and PDL cell adhesion. J Int Acad Periodontol 5, $11-22$

31. Adriaens PA, De Boever JA, Loesche WJ (1988) Bacterial invasion in root cementum and radicular dentin of periodontally diseased teeth in humans. A reservoir of periodontopathic bacteria.J Periodontol 59, 222-230 